University of New Orleans

ScholarWorks@UNO

Physics Faculty Publications

Department of Physics

1997

\title{
Optical studies of Ge islanding on $\mathrm{Si}(111)$
}

P. D. Persans

P. W. Deelman

K. L. Stokes

University of New Orleans

L. J. Schowalter

A. Byrne

See next page for additional authors

Follow this and additional works at: https://scholarworks.uno.edu/phys_facpubs

Part of the Physics Commons

\section{Recommended Citation}

Appl. Phys. Lett. 70, 472 (1997)

This Article is brought to you for free and open access by the Department of Physics at ScholarWorks@UNO. It has been accepted for inclusion in Physics Faculty Publications by an authorized administrator of ScholarWorks@UNO.

For more information, please contact scholarworks@uno.edu. 


\section{Authors}

P. D. Persans, P. W. Deelman, K. L. Stokes, L. J. Schowalter, A. Byrne, and T. Thundat 


\title{
Optical studies of $\mathrm{Ge}$ islanding on $\mathrm{Si}(111)$
}

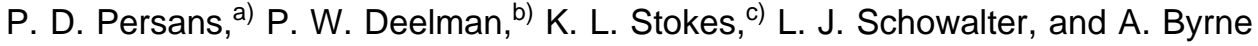 \\ Department of Physics, Applied Physics, and Astronomy and Center for Integrated Electronics \\ and Electronics Manufacturing, Rensselaer Polytechnic Institute, Troy, New York 12180
}

T. Thundat

Oak Ridge National Laboratory, Oak Ridge, Tennessee 37831

(Received 12 August 1996; accepted for publication 20 November 1996)

\begin{abstract}
We report an experimental study of the optical properties of island layers resulting from molecular beam epitaxial deposition of $\mathrm{Ge}$ on $\mathrm{Si}(111)$ substrates. The combination of electroreflectance spectroscopy of the $\mathrm{E}_{1}$ transition and Raman scattering allows us to separately determine the strain and composition of the islands. For deposition at $500{ }^{\circ} \mathrm{C}$ a deposited layer of $1.36 \mathrm{~nm}$ of Ge assembles into $80 \mathrm{~nm}$ diameter islands $11 \mathrm{~nm}$ thick. The average Si impurity content in the islands is $2.5 \%$ while the average in-plane strain is $0.5 \%$. Both strain and $\mathrm{Si}$ impurity content in islands decrease with increasing Ge deposition. (C) 1997 American Institute of Physics.

[S0003-6951(97)02904-5]
\end{abstract}

Epitaxial germanium nanoparticles are of great interest because it may be possible to tailor their optical and electronic properties using both three-dimensional quantum confinement and strain. When such nanoparticles are embedded in silicon, there is the possibility of combining a novel optical material with well-established, silicon-based device technologies.

Extensive work has been reported on the preparation and properties of $\mathrm{Si}_{\mathrm{x}} \mathrm{Ge}_{1-\mathrm{x}}$ strained layers and superlattices, ${ }^{1,2}$ $\mathrm{Si} / \mathrm{Ge}$ strained-layer superlattices, ${ }^{3}$ and on the pseudomorphic growth and islanding of $\mathrm{Ge}$ on $\mathrm{Si}(001) .{ }^{4-6}$ There has been a parallel effort to grow nanometer-size Ge particles embedded in various media in order to observe and exploit quantum confinement effects. ${ }^{7,8}$ Growth of epitaxial germanium nanoparticle island films on the silicon (111) surface by molecular beam epitaxy poses new opportunities and new problems. The growth thermodynamics and kinetics will be very different from that of the (001) surface. Strain will play a different role because of the new symmetry axis. Compared to the number of studies addressing $\mathrm{Ge} / \mathrm{Si}(100)$ growth, relatively little work has been published that addresses Ge/ $\mathrm{Si}(111)$ growth. ${ }^{9,10}$

In this letter we report on the use of optical spectroscopy to elucidate the growth and electronic properties of these nanoparticle island films. We combine electroreflectance spectroscopy on the $E_{1}$ optical transitions and Raman scattering to separate strain and compositional effects on the electronic structure.

Details on the growth and structural characterization of similar samples are given elsewhere. ${ }^{9}$ Nucleation and growth of $\mathrm{Ge} / \mathrm{Si}(111)$ films is by the Stranski-Krastanov mechanism in which a two-dimensional wetting layer with a thickness of 3-5 monolayers is first formed, and strain relief in thicker layers leads to three-dimensional island growth. The size and aspect ratio of the islands can be controlled by varying growth time and growth conditions. For the present samples, Ge was deposited on $\mathrm{Si}(111)$ wafers at $500{ }^{\circ} \mathrm{C}$. Silicon buffer

\footnotetext{
a)Electronic mail: persap@rpi.edu

${ }^{b}$ Present address: Jet Propulsion Laboratories, Pasadena, CA.

${ }^{c}$ Present address: Naval Research Laboratories, Washington, D.C.
}

layers approximately $20 \mathrm{~nm}$ thick were grown at $700{ }^{\circ} \mathrm{C}$ at a rate of $0.1 \mathrm{~nm} / \mathrm{s}$ just prior to Ge deposition. The nominal deposition thickness was varied from $1.3 \mathrm{~nm}$ to $5.2 \mathrm{~nm}$ in one run using a shutter as a shadow mask. An additional sample with a $50 \mathrm{~nm}$ Ge deposit was also prepared at a higher growth rate. The samples are identified here by the equivalent Ge-layer thickness, which was determined by Rutherford backscattering. Growth, structural, and spectroscopic data are summarized in Table I.

Electroreflectance spectroscopy of the $\mathrm{E}_{1}$ transition was carried out using a sandwich structure. ${ }^{11}$ The typical externally applied ac surface field was $1.4-7 \times 10^{4} \mathrm{~V} / \mathrm{cm}(\mathrm{rms})$. The optical system is described in detail elsewhere. ${ }^{12}$ The modulated reflectance signal was detected using a phasesensitive lock-in amplifier tuned in-phase to the electric field driving frequency $(1100 \mathrm{~Hz})$.

The Raman scattering system is also described in detail elsewhere. ${ }^{13}$ All spectra were excited with the $514.5 \mathrm{~nm}$ and $488.1 \mathrm{~nm}$ lines of an Ar ion laser in a near-backscattering VV-polarization configuration from the (111) surface. The entrance and exit slits were set to give an instrument resolution of about $5 \mathrm{~cm}^{-1}$. The Ge-like optical peak positions are given in Table I along with the areas of the peaks.

The integrated area of the Ge and Si Raman peaks can be used to determine the relative fractions of $\mathrm{Ge}$ and $\mathrm{Si}$ volume probed. The Ge peak area depends on the fractional area of the surface covered with islands $\left(f_{i}\right)$, the thickness of the islands $\left(d_{i}\right)$, and the thickness of the wetting layer $\left(d_{w}\right)$ :

$$
I_{\mathrm{Ge}} \propto\left[f_{i}\left(1-\exp \left(-2 \alpha d_{i}\right)\right) / 2 \alpha+\left(1-f_{i}\right) d_{w}\right],
$$

where $\alpha\left(\sim 7 \times 10^{6} \mathrm{~cm}^{-1}\right)$ is the absorption coefficient at the laser energy. From the fact that the Ge-peak Raman signal scales with island area [deduced from atomic force microscopy (AFM)], we conclude that our Raman signal is predominantly from the islands, rather than from the wetting layer.

Electroreflectance (ER) spectra between 2 and $2.5 \mathrm{eV}$ are shown in Fig. 1. We observe a strong ER peak at 2.1$2.3 \mathrm{eV}$ which is attributed to the $\mathrm{E}_{1}$ critical point. The magnitude of the ER signal increases with island area from 26 ppm for $f_{i}=0.08(1.36 \mathrm{~nm})$ to $260 \mathrm{ppm}$ for $f_{i}=0.4(5.2 \mathrm{~nm})$ 
TABLE I. Structural and optical data summary for Ge layers deposited at $500{ }^{\circ} \mathrm{C}$ on $\mathrm{Si}(111)$.

\begin{tabular}{|c|c|c|c|c|c|c|c|c|c|}
\hline $\begin{array}{c}\text { Film thickness } \\
\qquad(\mathrm{nm}) \\
(\mathrm{RBS})^{\mathrm{a}}\end{array}$ & $\begin{array}{l}\text { Island diameter } \\
(\mathrm{nm}) \\
(\mathrm{AFM})\end{array}$ & $\begin{array}{l}\text { Island thickness } \\
\text { (nm) } \\
\text { (AFM) }\end{array}$ & $\begin{array}{l}\text { Ge-Ge Raman position } \\
\qquad\left(\mathrm{cm}^{-1}\right)\end{array}$ & $\begin{array}{l}\text { Ge-Ge Raman area } \\
\left(\mathrm{cps} \mathrm{cm}^{-1}\right)\end{array}$ & $\begin{array}{c}\mathrm{E}_{1} \text { position } \\
(\mathrm{eV}) \\
(\mathrm{ER})\end{array}$ & $\begin{array}{c}\mathrm{E}_{1} \text { strength } \\
\text { (ppm) } \\
(\mathrm{ER})\end{array}$ & $\begin{array}{c}f_{i} \\
(\mathrm{AFM})\end{array}$ & $\begin{array}{c}\epsilon_{\|} \\
(\%)\end{array}$ & $\begin{array}{c}x \\
(\%)\end{array}$ \\
\hline 1.36 & 80 & 11 & 300.5 & 90 & 2.24 & 26 & 0.08 & $\begin{aligned} & 0.45 \\
\pm & 0.1\end{aligned}$ & $\begin{array}{r}3 \\
\pm 1\end{array}$ \\
\hline 3.2 & 150 & 12 & 300.9 & 170 & 2.18 & 260 & 0.4 & $\begin{array}{r}0.3 \\
\pm 0.1\end{array}$ & $\begin{array}{r}1 \\
\pm 1\end{array}$ \\
\hline 5.2 & 200 & 18 & 300.2 & 190 & 2.14 & 250 & 0.4 & $\begin{array}{c}0 \\
\pm 0.1\end{array}$ & $\begin{array}{r}1 \\
\pm 1\end{array}$ \\
\hline 50 & $\ldots$ & $\cdots$ & 300.5 & 450 & 2.13 & 550 & 1.0 & $\ldots$ & $\ldots$ \\
\hline
\end{tabular}

and $550 \mathrm{ppm}$ for the $50 \mathrm{~nm}$ layer. The built-in dc surface field should also affect the magnitude of the response at the fundamental driving frequency, but it does not appear to change significantly from sample to sample. We estimate a built-in dc surface field of $4-7 \times 10^{6} \mathrm{~V} / \mathrm{cm}$ by comparing the in-phase response at the fundamental driving frequency with the quadrature response at twice the driving frequency.

Confinement, strain, and Si alloying will all cause shifts of both electronic transition energies and vibrational energies. We neglect confinement effects on both electrons and phonons in the analysis here because the island dimensions are quite large. Estimated electronic confinement shift for the average island in the thinnest deposit is $<10 \mathrm{meV} .{ }^{14}$ Phonon modes are not localized in the (111) direction by this structure. ${ }^{15}$ We show here how to quantify the strain and alloying effects by requiring two separate measurements to fit the same strain/composition combination.

The shift in Raman frequency induced by in-plane surface strain of $\varepsilon_{\|}$can be broken into two parts: the hydrostatic strain part and the uniaxial strain part. ${ }^{16}$ Biaxial strain in the plane of the surface $\left(\varepsilon_{\|}\right)$gives rise to hydrostatic strain of $\varepsilon_{H}=0.815 \varepsilon_{\|}$and uniaxial strain $\varepsilon_{\perp}=-1.18 \varepsilon_{\|} \cdot{ }^{16}$ Using parameters for $\mathrm{Ge}$ deduced from hydrostatic compressive stress measurements, ${ }^{17}$ we estimate the hydrostatic part of the shift: $\Delta \Omega_{H}=-730 \varepsilon_{\|}\left(\mathrm{cm}^{-1}\right)$. The uniaxial part of the strain along the [111] direction $\left(\varepsilon_{\perp}\right)$ splits the longitudinal optical (LO) phonon modes into a singlet, propagating along the [111] axis, and a doublet. The shift of the singlet due to the

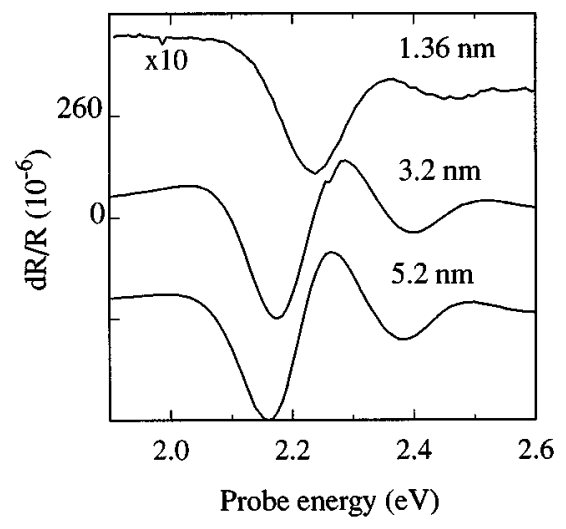

FIG. 1. Electroreflectance of Ge layers on Si(111). Deposition thicknesses vary from $1.1 \mathrm{~nm}$ to $50 \mathrm{~nm}$ as marked. The spectra were taken at room temperature with the lock-in set in-phase at the fundamental driving frequency. Spectra are offset vertically by \pm 260 ppm for clarity. uniaxial strain is given by ${ }^{18} \Delta \Omega_{s} \cong-470 \varepsilon_{\|}$; thus the overall (hydrostatic + uniaxial) shift of the singlet is

$$
\Delta \Omega_{s} \cong-260 \varepsilon_{\|} .
$$

The biaxial strain-induced shift of the $\mathrm{Ge}_{1}$ point was calculated recently by Tserbak and Theodorou. ${ }^{19}$ The $\mathrm{E}_{1}$ optical critical point structure in unstrained Ge is due to transitions between parallel bands along the $\Lambda$ direction and close to the $\mathrm{L}$ point. In unstrained $\mathrm{Ge}, \mathrm{E}_{1}=2.10 \mathrm{eV}$. When $\mathrm{Ge}$ is grown on the (111) surface of $\mathrm{Si}\left(\varepsilon_{\|}=4 \%\right)$, the $\mathrm{L}$ point splits into two nonequivalent points, $\mathrm{Z}$ and $\mathrm{L}$. The energy of the lowest transition in strained $\mathrm{Ge} / \mathrm{Si}(111)$ is 2.18 $\mathrm{eV}$ at the $\mathrm{L}$ point and $2.7 \mathrm{eV}$ at the $\mathrm{Z}$ point. Expressing the strain-energy relation from Ref. 19:

$$
\Delta \mathrm{E}_{1}(\mathrm{~L})=-1.2 \mathrm{eV} \varepsilon_{\|}
$$

and

$$
\Delta \mathrm{E}_{1}(\mathrm{Z})=-14 \mathrm{eV} \varepsilon_{\|} .
$$

Putting together the $\mathrm{E}_{1}$ and $\Delta \Omega_{s}$ dependence on strain, we get the parametric relations for biaxial in-plane strain $\Delta \Omega_{s}\left(\mathrm{~cm}^{-1}\right)=19 \Delta E_{1}(Z)(\mathrm{eV})$ and $\Delta \Omega_{s}\left(\mathrm{~cm}^{-1}\right)$ $=220 \Delta E_{1}(L)(\mathrm{eV})$, shown as the dashed line in Fig. 2.

The compositional effect on Raman mode energies and on the $E_{1}$ transition energy is easily deduced from reported measurements. The Ge-Ge mode energy of $\mathrm{Ge}_{1-x} \mathrm{Si}_{\mathrm{x}}$ decreases nearly linearly with $x$ for small $x:{ }^{20}$

$$
\Delta \Omega=-37 x \mathrm{~cm}^{-1} .
$$

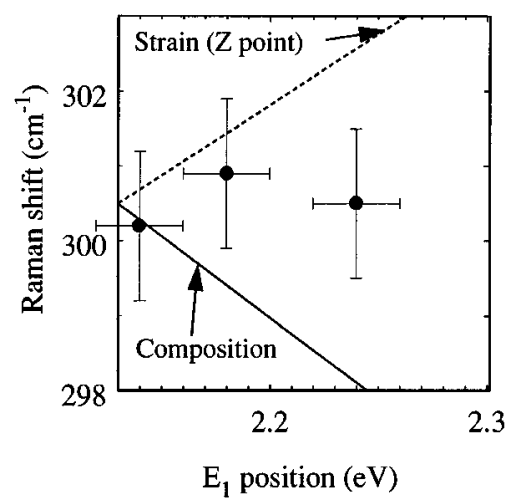

FIG. 2. Plots of the relation between the Ge-Ge Raman mode energy and the $E_{1}(Z)$ and $E_{1}(L)$ optical transition energies with strain and $\mathrm{Si}$ content as parameters (dashed lines). Data points are the measured values. 
The $\mathrm{E}_{1}(\mathrm{~L})$ point shifts up in energy linearly with $x$ according to ${ }^{3}$

$$
\Delta E_{1}=1.2 x(\mathrm{eV}) \text {. }
$$

In a parametric plot of $E_{1}$ and $\Delta \Omega$ we would then have $\Delta \Omega=-31 \Delta E_{1}(\mathrm{eV})$, shown in Fig. 2 . The intensity of the Si-Ge Raman mode at $390-410 \mathrm{~cm}^{-1}$ can provide a more direct measure of $\mathrm{Si}$ alloying with $\mathrm{Ge}$ than the position of the Ge-Ge mode alone (which is also sensitive to strain). Quantitative comparison to a thick $\mathrm{Si}_{0.3} \mathrm{Ge}_{0.7}$ layer sets upper limits of $10 \% \mathrm{Si}$ in $\mathrm{Ge}$ for the $1.3 \mathrm{~nm}$ layer, $4 \% \mathrm{Si}$ in $\mathrm{Ge}$ for the $5 \mathrm{~nm}$ layer, and $2 \% \mathrm{Si}$ in the $50 \mathrm{~nm}$ layer. The measured energy of the $E_{1}$ feature shifts monotonically from $2.13 \mathrm{eV}$ for the $50 \mathrm{~nm}$ film to $2.24 \mathrm{eV}$ for the $1.3 \mathrm{~nm}$ deposit. We have plotted the Raman shift against the $\mathrm{E}_{1}$ position in Fig. 2. While the three thicker samples could be consistent with either the pure-strain or pure-compositional shifts, the thinnest sample is clearly neither. The combination of very small shift $\left(0 \pm 0.5 \mathrm{~cm}^{-1}\right)$ in Raman peak position and the shift of $+0.11 \mathrm{eV}$ in $\mathrm{E}_{1}$ position is due to a combination of strain and composition effects. Equations (1), (3), and (4) are experimentally valid for up to several percent $\mathrm{Si}$ in $\mathrm{Ge}$. If we make the plausible assumption that $\mathrm{Si}$ impurity in the Ge layer has little effect on Eq. (3), then Eqs. (1)-(4) can be combined to deduce $\varepsilon_{\|}$and $x$ :

$$
\varepsilon_{\|}=-0.045 \Delta E_{1}-0.0014 \Delta \Omega
$$

and

$$
x=0.315 \Delta E_{1}-0.017 \Delta \Omega .
$$

Values deduced from the data and from Eqs. (5) are given in Table I. The $1.3 \mathrm{~nm}$ layer has the largest strain and Si content, $0.45 \%$ and $3 \%$ respectively. Both strain and $\mathrm{Si}$ content decrease with increasing coverage. We note that the strain and composition found here are average values for which the relative weighting depends on a response to a particular optical technique. For example, electroreflectance response may depend on island thickness (through the built-in field) as well as island area.

Using AFM, we observe that the main differences between islands for low- and high-coverage samples are the island diameter and density. Island thickness only changes slowly with nominal coverage. If Si were diffusing from the substrate for fixed island thickness, we would expect the surface Si content to increase with deposition time. This is not observed, therefore diffusion is not an important mixing mechanism. Instead, the average Si content drops in a manner that suggests that there is a fixed amount of $\mathrm{Si}$ that be- comes increasingly diluted in $\mathrm{Ge}$ as the islands grow. One possible explanation for such behavior is a surface exchange mechanism in which a fraction of the $\mathrm{Si}$ and $\mathrm{Ge}$ atoms in the outermost two layers of the growth front can exchange. ${ }^{4} \mathrm{Af}-$ ter nucleation, growth is mostly lateral, so the $\mathrm{Si}$ available for exchange at the growth front would decrease with island diameter, and the average Si content would drop in approximate proportion to the inverse island volume (nominal film thickness).

We have shown how a combination of resonant Raman scattering and electroreflectance spectroscopy can be used to separate strain and composition effects on the properties of epitaxial Ge on $\mathrm{Si}(111)$. We were able to detect low levels (a few percent) of Si alloying in Ge islands. The observed shifts in the $\mathrm{E}_{1}$ critical point with equivalent deposit thickness at $500{ }^{\circ} \mathrm{C}$ are due to both residual strain and $\mathrm{Si}$ impurity.

This work was supported in part by NSF Grant Nos. DMR-9104086 and DMR-9203183. The authors are grateful to H. S. Kang (Chonbuk University, Seoul, South Korea) and $\mathrm{S}$. Harris for assistance with Raman scattering measurements.

${ }^{1}$ F. Cerdeira, A. Pinuck, J. C. Bean, B. Batlogg, and B. A. Wilson, Appl. Phys. Lett. 45, 1138 (1984).

${ }^{2}$ S. C. Jain, J. R. Willis, and R. Burrough, Adv. Phys. 39, 127 (1990).

${ }^{3}$ T. P. Pearsall, J. Lumin. 44, 367 (1989).

${ }^{4}$ W. Kissinger, H. J. Osten, G. Lippert, B. Dietrich, and E. Nugiel, J. Appl. Phys. 76, 8042 (1994).

${ }^{5}$ D. J. Eaglesham and M. Cerullo, Phys. Rev. Lett. 64, 1943 (1990).

${ }^{6}$ M. Hammar, F. K. LeGoues, J. Tersoff, M. C. Reuter, and R. M. Tromp, Surf. Sci. 349, 129 (1996).

${ }^{7}$ D. C. Paine, C. Caragianis, T. Kim, Y. Sigesato, and T. Ishahara, Appl. Phys. Lett. 62, 2842 (1993)

${ }^{8}$ Y. Sasaki and C. Horie, Phys. Rev. B 48, 2009 (1993); 47, 3811 (1993).

${ }^{9}$ P. W. Deelman, L. J. Schowalter, and T. Thundat, Mater. Res. Soc. Symp. Proc. 399, 295 (1996).

${ }^{10}$ F. K. LeGoues, M. Hammar, M. C. Reuter, and R. M. Tromp, Surf. Sci. 349, 249 (1996).

${ }^{11}$ B. O. Seraphin, R. B. Hess, and N. Bottka, J. Appl. Phys. 36, 2242 (1965).

${ }^{12}$ K. L. Stokes and P. D. Persans, Phys. Rev. B 54, 1892 (1996).

${ }^{13}$ P. D. Persans, Phys. Rev. B 39, 1797 (1989).

${ }^{14}$ P. Tognini, L. C. Andreani, M. Geddo, A. Stella, P. Cheyssac, R. Kofman, and A. Migliori, Phys. Rev. B 53, 6992 (1996).

${ }^{15}$ J. Tsang, S. S. Iyer, P. Pukite, and M. Copel, Phys. Rev. B 39, 13545 (1989).

${ }^{16}$ S. Hashimoto, J.-L. Peng, W. M. Gibson, L. J. Schowalter, and R. W. Fathauer, Appl. Phys. Lett. 47, 1071 (1986).

${ }^{17}$ J. B. Renucci, M. A. Renucci, and M. Cardona, Solid State Commun. 9, 1651 (1971)

${ }^{18}$ F. Cerdeira, C. J. Buchenauer, F. H. Pollack, and M. Cardona, Phys. Rev. B 5, 580 (1972).

${ }^{19}$ C. Tserbak and G. Theodorou, Phys. Rev. B 52, 12232 (1995).

${ }^{20}$ M. A. Renucci, J. B. Renucci, and M. Cardona, in Light Scattering in Solids, edited by A. Balkanski (Flammarion, Paris, 1971), p.326. 